\title{
Energy Production in Solar Collectors in a University Building Used to Improve the Internal Thermal Conditions in Winter Conditions
}

\author{
Eusébio Conceição ${ }^{1 *}$, João Gomes ${ }^{2}, M^{a}$ Manuela Lúcio $^{1}$ and Hazim Awbi $^{3}$ \\ ${ }^{1}$ FCT - University of Algarve, Campus de Gambelas, 8005-139 Faro, Portugal \\ ${ }^{2}$ CINTAL, Campus de Gambelas, 8005-139 Faro, Portugal \\ ${ }^{3}$ School of Built Environment, University of Reading, Reading, RG6 6AW, UK
}

\begin{abstract}
In this numerical study the energy production in solar collectors in a University building used to improve the internal thermal conditions is made. Passive and active solutions, using external solar collector and internal thermo-convectors, are used. The numerical simulation, in transient conditions, is done for a winter typical day with clean sky. This numerical study was carried out using a software that simulates the Building Dynamic Response with complex topology in transient conditions. The software evaluates the human thermal comfort and indoor air quality levels that the occupants are subjected, Heated Ventilation and Air Conditioned energy consumption, indoor thermal variables and other parameters. The university building has 107 compartments and is located in a Mediterranean-type environment. External solar water collectors, placed above the building's roof, and internal thermo-convectors of water/air type, using mixing ventilation, are used as passive and active strategies, respectively. The thermal comfort level, using the Predicted Mean Vote index, and the indoor air quality, using the carbon dioxide concentration, are evaluated. The results show that in winter conditions the solar collectors improve the thermal comfort conditions of the occupants. The indoor air quality, in all ventilated spaces, is also guaranteed.
\end{abstract}

\section{Introduction}

In Portugal, there has been a significant increase in energy consumption in buildings, driven in part by the intensive use of Heated Ventilation and Air Conditioned (HVAC) system equipment and the dissipative behaviour of the building. In this context, the need to develop HVAC systems that enable thermal comfort levels to be maintained with sustainable low energy consumption becomes imperative.

This study is associated with the development and application of a solar HVAC system. The HVAC system of the building's compartments, in winter conditions, is carried out using solar thermal energy. The objectives are to obtain numerically the level of thermal comfort and the quality of the indoor air to which the occupants of the rooms are exposed. The HVAC system simulated uses solar panels that, through a system of ducts, which will provide the heating of the rooms interior by thermoconvectors.

Several works were developed in the application of thermal solar collectors. In the work of Kalogirou et al. [1] the review of exergy analysis in solar thermal collectors was analysed. In the work of Suman et al. [2] a review performance of solar collectors was made. In the work of Jamar et al. [3] a review of the water heating system for solar energy applications was analysed.

Several parameters are used in the evaluation of the thermal comfort and indoor air quality, namely, Predicted Mean Vote (PMV) index, Predicted Percentage of Dissatisfied (PPD) index and carbon dioxide $\left(\mathrm{CO}_{2}\right)$ concentration. $\mathrm{CO}_{2}$ concentration can be used to evaluate indoor air quality [4-6]. PMV and PPD, see Fanger [7], are applied to determine the thermal comfort conditions in conditioned spaces and they are used by ISO 7730 [8] and ASHRAE 55 [9] to define three thermal comfort categories (A, B, C) requirements.

In this study a software, that simulate the Building Dynamic Response, which evaluates the air temperature distribution, surfaces temperature distribution and energy consumption is used (see the works of Conceição and Lúcio [10,11]). The software considers the evaluation of thermal comfort through the PMV/PPD indexes [12], adaptive thermal comfort [13], and temperature control model [14]. The study of Conceição et al. [12] shows also a control methodology of the HVAC system based on PMV.

This kind of simulation was made by others authors using others numerical models. The wall building thermal performance is study in Balaji et al. [15], a

* Corresponding author: econcei@ualg.pt 
review of the building thermal comfort and building energy consumption are presented in Yang et al. [16], and the building energy simulation model of green roof is shown in Sailor [17].

In order to evaluate the occupant thermal comfort level, that each occupant is subjected, and the airflow topology inside each space, the results obtained in this software can be used in others software that consider a coupling of Computer Fluid Dynamics (CFD) and Human Thermal Response (HTR) numerical models. This methodology can be seen in the studies of Conceição and Lúcio [18-20], Conceição [21], and Conceição et al. [22,23].

The thermal comfort is a topic analysed, in the last years, by several authors. Examples can be showed in the works of Ekici [24], Fabbri [25], and Pourshaghaghy and Omidvari [26]. In Ekici [24], a review of thermal comfort and a review method of the application of the Fanger's PMV and PPD equations is analysed. Fabbri [25] used the thermal comfort level in the evaluation of kindergarten spaces comfort conditions is analysed. In this study measurements of PPD and PMV indexes and questionnaire are used. Pourshaghaghy and Omidvari [26] used the PPV and PPD indexes in order to evaluate the thermal comfort in a hospital environment.

In this study, it is used a new methodology to heating the occupied spaces through a natural renewable energy source, particularly, solar energy. The process is based on the application of solar thermal collectors, placed above a university roof area, to heat water which will be used inside the occupied compartments by thermoconvectors. The HVAC system, based on a set of thermo-convectors, will be controlled by a PMV index control system in order to guarantee acceptable thermal comfort levels within category C [8].

The main objective of this work is from a passive solar solution, using solar thermal collectors, and from an active solution, control of the HVAC system, to guarantee acceptable thermal comfort levels within the occupied compartments, keeping the PMV index at least within the category $\mathrm{C}$, and acceptable levels of indoor air quality, keeping the $\mathrm{CO}_{2}$ concentration below 1800 $\mathrm{mg} / \mathrm{m}^{3}$, for winter conditions. The use of these two solutions will allow to obtain energy gains, in addition to promoting the use of a renewable energy source in the implementation of HVAC systems.

\section{Numerical Model}

In this numerical simulation, a research software, developed by the authors over the past two decades, was used to evaluate the Building Dynamic Response. The numerical model, that simulate the Building Dynamic Response, can be analysed, for example, in Conceição et al. [27] and Conceição and Lúcio [28]. In these works, all main equations and all main coefficients are presented. These studies presented different applications, however, in both applications the thermal response, the energy consumption and the thermal comfort are analysed in detail. The software used in this work was validated, using school buildings, for winter conditions in Conceição et al. [29] and for summer conditions in Conceição and Lúcio [30].

The numerical model is based on the balance of mass and energy integral equations. The mass balance integral equations are considering for the water vapour and the air contaminants. These equations are developed for the spaces of the buildings and the solid matrix (opaque and interior bodies). The energy balance integral equations are taken for the indoor air of the compartments, the transparent (windows) bodies of the building, the interior and surroundings bodies of the building and the opaque (walls and doors) bodies of the building. The resolution of the equations system is done by the Runge-Kutta-Felberg method with error control. The outputs of the numerical software are the solar radiation evolution, radiation heat exchange, convection coefficients, indoor air temperature, indoor air velocity, dioxide carbon concentration, PMV and PPD thermal comfort indexes, among others.

This numerical model is used to calculate:

- the temperatures of indoor spaces,

- the temperature of opaque bodies (ceiling, floor, walls and others);

- The temperature of transparent bodies (windows);

- The temperature of the interior bodies.

The numerical model calculates also the:

- Concentration of contaminates (as carbon dioxide concentration);

- Concentration of water vapour.

In the assessment of the indoor air quality, the $\mathrm{CO}_{2}$ concentration is used. In the evaluation of the level of thermal comfort, the PMV index is used [7]. This index considers the values of the environmental and personal parameters. In the environmental parameters are considered the mean air velocity, mean air temperature, mean air relative humidity and mean radiant temperature. In the personal parameters this index considers the activity level and clothing level. In the monitoring and controlling the HVAC system, it will be used the PMV index [8].

\section{Numerical Methodology}

The building used in this work is an educational building (Figure 1) constituted essentially by classrooms, amphitheatres and an auditorium. It consists of 125 transparent surfaces, 1550 opaque surfaces and 107 compartments distributed between a ground floor and two upper floors, where teaching activities take place. The HVAC system will only be applied in the 33 occupied compartments.

This numerical simulation considers the internal occupation and ventilation. The selection of the airflow rate took into account the situation of occupation or nonoccupation of spaces. When the spaces are occupied, the airflow rate used was calculated according to the Portuguese standard [31]. When spaces are not 
occupied, it was used an airflow rate of one air renewal per hour.

In the numerical simulation, it was considered that the classrooms, laboratories and offices are occupied, in general, by periods of 90 minutes. The breaks considered between the occupation periods have a duration of 15 minutes. As the numerical simulation was performed for typical winter conditions, it was defined a clothing level of 1 clo [8]. The level of activity considered was 1.2 met [8].

A numerical simulation was made using 611 solar collectors (with dimensions $2 \times 1.1 \mathrm{~m}^{2}$ ) installed on the roof of the building (Figure 1) to provide heat to the air conditioning system, in winter conditions [32]. The collectors are placed together to make up rows. The heated water in the collectors is distributed throughout the building through a system of thermally insulated pipes. The HVAC system, worked as heating system, consider thermo-convectors installed on the ceiling of each occupied spaces. Figure 2 presents a system sketch for the technical system showing connections of the solar collectors to ducts and to internal thermoconvectors. Figure 2 also shows the airflow patterns in the room.

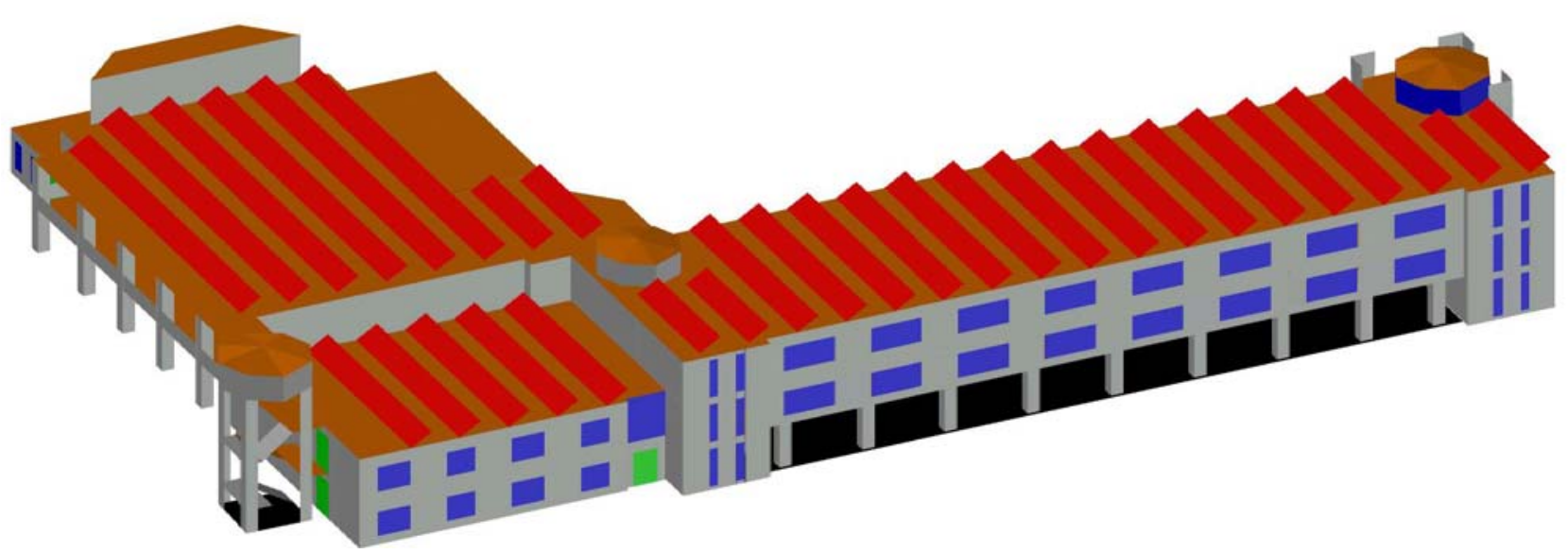

Figure 1. South-east view of the external perspective of the university building with solar collectors (red colour) installed on the roof.

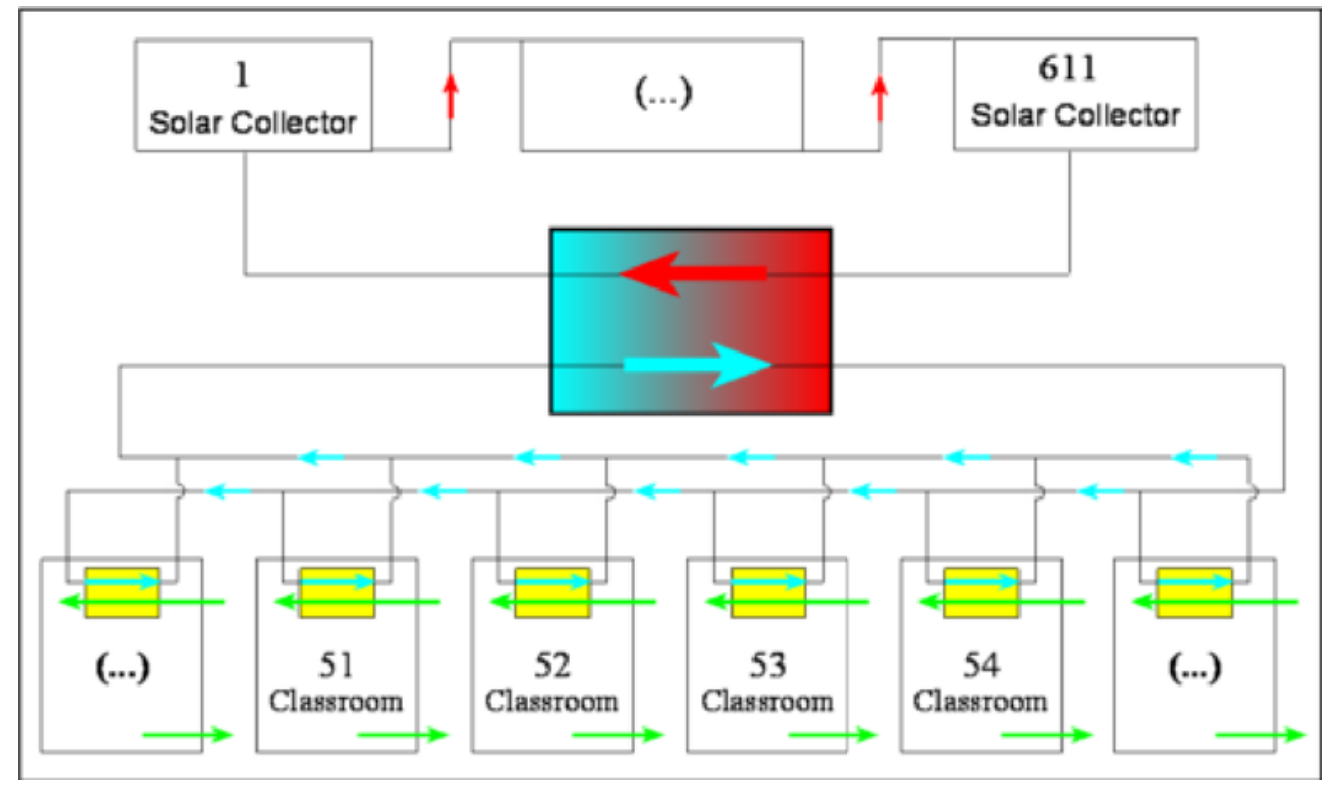

Figure 2. Scheme of circuits between solar collectors, fluid deposit, and classrooms: in red, hot water circuit; in blue, cold water circuit. In addition, it is visible the airflow (green colour) inside of classrooms in contact with a heat exchanger.

\section{Results}

This section presents the results obtained of the average indoor air temperature (Figure 3), indoor thermal comfort level (Figure 4), using average PMV index, and indoor air quality level (Figure 5), using $\mathrm{CO}_{2}$ concentration, for four classrooms with East-facing windows. Figures 3 and 4 also shown, comparatively, the evolution of indoor air temperature and PMV index 
without and with the application of a solar renewable energy system. The perception of the thermal comfort of the occupants is given by the PMV index. The PMV index presented corresponds to the average value obtained in the occupied area. This value is obtained according to the average values of the air temperature, the air speed and the relative humidity of the air obtained in the occupied area. The PMV also depends on the average radiant temperature obtained in the center of the occupied area due to the existing radiative exchanges with the surrounding surfaces. In addition to the environmental parameters, the PMV index also considers the personal parameters given by the average level of clothing ( 1.0 clo in winter conditions) of the occupants and by their level of activity (1.2 met). The perception of indoor air quality is given by the average concentration of $\mathrm{CO}_{2}$ in the occupation area.

The results show that the use of the solar HVAC system allows to increase, on average, the indoor air temperature of the classrooms by $4^{\circ} \mathrm{C}$ to a value around $20^{\circ} \mathrm{C}$. However, the behaviour of this system is not so significant in the morning because there is not enough energy available.

When the space is occupied and the solar HVAC system is used, the control of this system through the PMV index allows to guarantee acceptable levels of thermal comfort within category $\mathrm{C}$ (PMV between -0.7 and +0.7 ) of ISO 7730 [8] by negative values of PMV index. The HVAC solar heating system is connected when the PMV value is lower than -0.7 and disconnected when the PMV value is higher than -0.7 .

Finally, the ventilation topology used guarantees acceptable indoor air quality according to the ASHRAE 62.1 standard [4].

The results of the simulation, carried out for winter conditions, show that the solar HVAC system produces enough energy to provide acceptable levels of thermal comfort and indoor air quality in all rooms throughout the occupation regime.

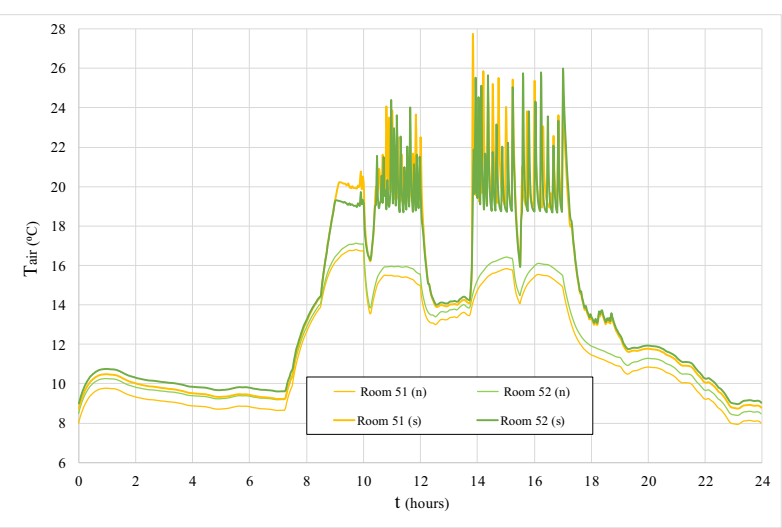

Figure 3. Evolution of air temperature ( $\left.\mathrm{T}_{\text {air }}\right)$ on the rooms, in the East side building, in winter conditions, the classrooms 51 and 52 , where the thin line is associated with none (n) solar renewable energy system, while the thick line is associated with (s) solar renewable energy system.

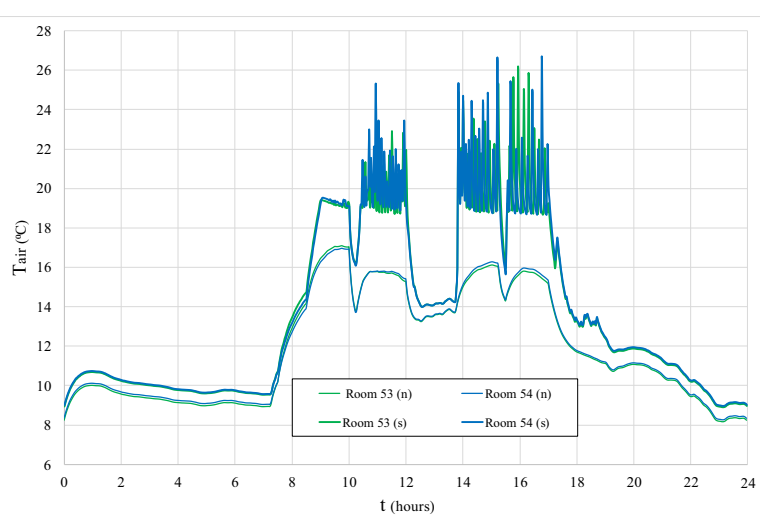

Figure 4. Evolution of air temperature ( $\left.\mathrm{T}_{\text {air }}\right)$ on the rooms, in the East side building, in winter conditions, the classrooms 53 and 54. The thin line is associated with none (n) solar renewable energy system, while the thick line is associated with (s) solar renewable energy system.

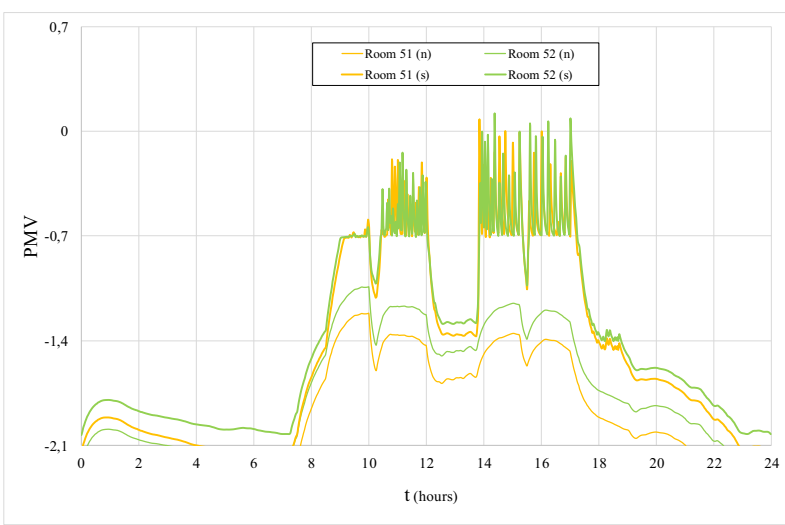

Figure 5. Evolution of PMV index on the rooms, in the East side building, in winter conditions, the classrooms 51 and 52, whereas the thin line is associated with none (n) solar renewable energy system, while the thick line is associated with (s) solar renewable energy system.

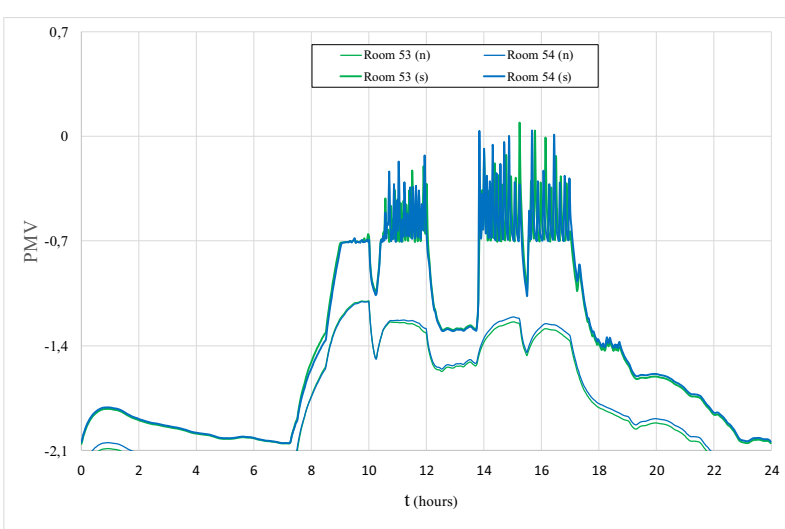

Figure 6. Evolution of PMV index on the rooms, in the East side building, in winter conditions, the classrooms 53 and 54, whereas the thin line is associated with none (n) solar renewable energy system, while the thick line is associated with (s) solar renewable energy system. 


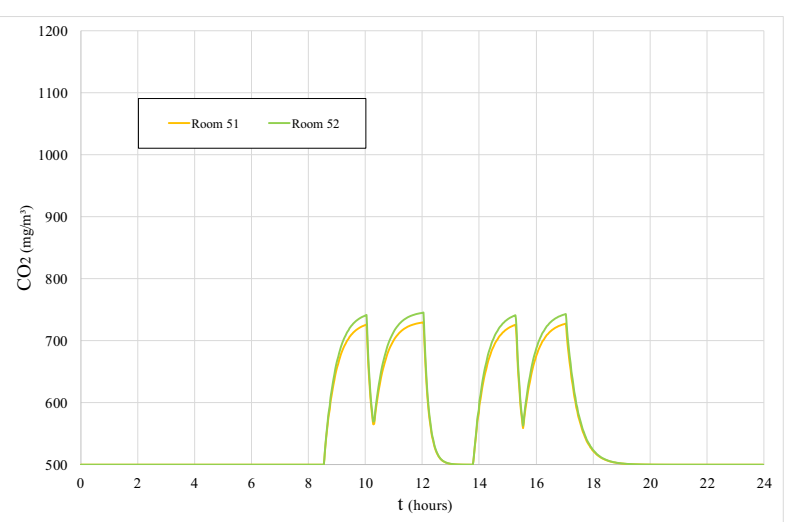

Figure 7. Evolution of $\mathrm{CO}_{2}$ concentration in the rooms, in the East side building, in winter conditions, the classrooms 51 and 52.

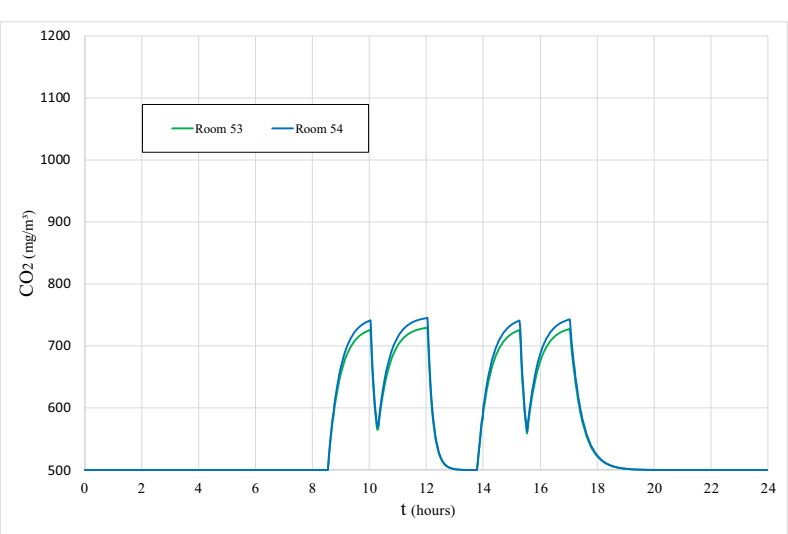

Figure 8. Evolution of $\mathrm{CO}_{2}$ concentration in the rooms, in the East side building, in winter conditions, the classrooms 53 and 54.

\section{Conclusion}

This work presented an analysis of the energy production in solar collectors in a university building used to improve the internal thermal conditions in winter conditions. The numerical study was developed through a Building Dynamic Response software. In this study a HVAC system, based on the use of solar energy produced in collectors and with control of the PMV index, were developed.

The use of the solar HVAC system, with control of the PMV index, makes it possible to guarantee acceptable levels of thermal comfort for occupants within category $\mathrm{C}$ [8]. The air temperature inside these four compartments rises to around $20^{\circ} \mathrm{C}$. The indoor ventilation topology guarantees also acceptable levels of indoor air quality.

In a future work the solar HVAC system will be applied to improve the thermal conditions of all occupied rooms in the building. It will be assessed whether the energy production will be sufficient to guarantee acceptable levels of thermal comfort in winter conditions.

\section{Acknowledgement}

The authors would like to acknowledge to the project (SAICT-ALG/39586/2018) from Algarve Regional
Operational Program (CRESC Algarve 2020), under the PORTUGAL 2020 Partnership Agreement, through the European Regional Development Fund (ERDF) and the National Science and Technology Foundation (FCT).

\section{References}

[1] S. A. Kalogirou, S. Karellas, K. Braimakis, C. Stanciu, and V. Badescu, "Exergy analysis of solar thermal collectors and processes," Progress in Energy and Combustion Science. 2016, doi: 10.1016/j.pecs.2016.05.002.

[2] S. Suman, M. K. Khan, and M. Pathak, "Performance enhancement of solar collectors A review," Renewable and Sustainable Energy Reviews. 2015, doi: 10.1016/j.rser.2015.04.087.

[3] A. Jamar, Z. A. A. Majid, W. H. Azmi, M. Norhafana, and A. A. Razak, "A review of water heating system for solar energy applications," International Communications in Heat and Mass Transfer. 2016, doi: 10.1016/j.icheatmasstransfer.2016.05.028.

[4] ASHRAE 62.1, "Ventilation for Acceptable Indoor Air Quality," J. Phys. A Math. Theor., 2016, doi: 10.1088/1751-8113/44/8/085201.

[5] Ministério da economia e do emprego, “Decreto-Lei 118/2013," Diário da República, 2013.

[6] E. Z. E. Conceição, M. M. J. R. Lúcio, V. D. S. R. Vicente, and V. C. T. Rosão, "Evaluation of local thermal discomfort in a classroom equipped with cross flow ventilation," Int. J. Vent., 2008, doi: 10.1080/14733315.2008.11683817.

[7] P. Ole Fanger, "Thermal comfort. Analysis and applications in environmental engineering.," Copenhagen Danish Tech. Press, 1970.

[8] ISO, "ISO 7730: Ergonomics of the thermal environment Analytical determination and interpretation of thermal comfort using calculation of the PMV and PPD indices and local thermal comfort criteria," Management, 2005, doi: 10.1016/j.soildyn.2004.11.005.

[9] ASHRAE-55, "Thermal environmental conditions for human occupancy," ANSI/ASHRAE Stand. - 55, 2017.

[10] E. Z. E. Conceição and M. M. J. R. Lúcio, "Numerical study of the influence of opaque external trees with pyramidal shape on the thermal behaviour of a school building in summer conditions," Indoor Built Environ., vol. 19 , no. 6,2010 , doi: 10.1177/1420326X10377546.

[11] E. Z. E. Conceição and M. M. J. R. Lúcio, "Numerical study of the thermal efficiency of a school building with complex topology for different orientations," Indoor Built Environ., vol. 18 , no. 1, 2009, doi: 


\section{$10.1177 / 1420326 X 08099550$.}

[12] E. Z. E. Conceição, J. M. M. Gomes, and A. E. Ruano, "Application of HVAC Systems with Control Based on PMV Index in University Buildings with Complex Topology," IFACPapersOnLine, vol. 51, no. 10, 2018, doi: 10.1016/j.ifacol.2018.06.230.

[13] E. Z. E. Conceição, A. R. L. Nunes, J. M. M. Gomes, and M. J. R. Lúcio, "Application of a school building thermal response numerical model in the evolution of the adaptive thermal comfort level in the Mediterranean environment," Int. J. Vent., vol. 9, no. 3, 2010, doi: 10.1080/14733315.2010.11683887.

[14] E. Z. E. Conceição, M. M. J. R. Lúcio, A. E. B. Ruano, and E. M. Crispim, "Development of a temperature control model used in HVAC systems in school spaces in Mediterranean climate," Build. Environ., vol. 44, no. 5, 2009, doi: 10.1016/j.buildenv.2008.06.015.

[15] N. C. Balaji, M. Mani, and B. V. Venkatarama Reddy, "Thermal performance of the building walls," 2013.

[16] L. Yang, H. Yan, and J. C. Lam, "Thermal comfort and building energy consumption implications - A review," Applied Energy. 2014, doi: 10.1016/j.apenergy.2013.10.062.

[17] D. J. Sailor, "A green roof model for building energy simulation programs," Energy Build., 2008, doi: 10.1016/j.enbuild.2008.02.001.

[18] E. Z. E. Conceição, M. M. J. R. Lúcio, and H. B. Awbi, "Comfort and airflow evaluation in spaces equipped with mixing ventilation and cold radiant floor," Build. Simul., vol. 6, no. 1, 2013, doi: 10.1007/s12273-012-0093-4.

[19] E. Z. E. Conceição and M. M. J. R. Lúcio, "Numerical simulation of the application of solar radiant systems, internal airflow and occupants' presence in the improvement of comfort in winter conditions," Buildings, vol. 6, no. 3, 2016, doi: 10.3390/buildings6030038.

[20] E. Z. E. Conceição and M. Lúcio, "Numerical and subjective responses of human thermal sensation," Proc. BioEng, 2001.

[21] E. Z. E. Conceição, "Evaluation of thermal comfort and local discomfort conditions using the numerical modelling of the human and clothing thermal system," in RoomVent'20007th International Conference on Air Distribution in Rooms, 2000, pp. 131-136.

[22] E. Z. E. Conceição, S. P. Rosa, A. L. V. Custódio, R. L. Andrade, M. J. P. A. Meira, and M. M. J. R. Lúcio, "Study of airflow around occupants seated in desks equipped with upper and lower air terminal devices for slightly warm environments," HVAC R Res., vol. 16 , no. 4,2010 , doi: 10.1080/10789669.2010.10390912.
[23] E. Z. E. Conceição, M. Lúcio, and J. P. Farinho, "Experimental and numerical study of personalized of ventilation in classrooms desks," in Proceedings of the 10th International Conference in Rooms, Room Vent, Helsinki, Finland, 2007, pp. 13-15.

[24] C. Ekici, "A review of thermal comfort and method of using Fanger's PMV equation," 2013.

[25] K. Fabbri, "Thermal comfort evaluation in kindergarten: PMV and PPD measurement through datalogger and questionnaire," Build. Environ., 2013, doi: 10.1016/j.buildenv.2013.07.002.

[26] A. Pourshaghaghy and M. Omidvari, "Examination of thermal comfort in a hospital using PMV-PPD model," Appl. Ergon., 2012, doi: 10.1016/j.apergo.2012.03.010.

[27] E. Z. E. Conceição, M. C. G. Da Silva, J. C. S. André, and D. X. Viegas, "Thermal behaviour simulation of the passenger compartment of vehicles," Int. J. Veh. Des., vol. 24, no. 4 , 2000, doi: 10.1504/IJVD.2000.005199.

[28] E. Z. E. Conceição and M. M. J. R. Lúcio, "Numerical simulation of passive and active solar strategies in buildings with complex topology," Build. Simul., vol. 3, no. 3, 2010, doi: 10.1007/s12273-010-0010-7.

[29] E. Conceição, A. Silva, and M. Lúcio, "Numerical study of thermal response of school buildings in winter conditions," In Proceedings of the $9^{\text {th }}$ Conference on Air Distribution in Rooms (Roomvent 2004), Coimbra, Portugal, September 5-8, 2004

[30] E. Conceição and M. Lúcio, "Numerical study of thermal response of school buildings in summer conditions," In Proceedings of the $8^{\text {th }}$ International Conference and Exhibition on Healthy Buildings (HB 2006), Lisbon, Portugal, June 4-8, 2006.

[31] Portaria n. 353-A/2013, "Regulamento de Desempenho Energético dos Edifícios de Comércio e Serviços (RECS) - Requisitos de Ventilação e Qualidade do Ar Interior," Diário da República. 2013.

[32] S. A. Kalogirou, "Solar thermal collectors and applications," Progress in Energy and Combustion Science. 2004, doi: 10.1016/j.pecs.2004.02.001. 